\title{
THE EFFECT OF MICROLEAKAGE IN CLASS V CAVITY USING SELF-ADHERING FLOWABLE COMPOSITE WITH THE ADDITION OF ACID ETCH
}

\author{
Dennis ${ }^{1}$, Darwis Aswal2, Anastasia ${ }^{3}$ \\ ${ }^{1}$ Faculty of Dentistry, University of Sumatera Utara. \\ ${ }^{2}$ Faculty of Dentistry, University of Sumatera Utara. \\ ${ }^{3}$ Faculty of Dentistry, University of Sumatera Utara.
}

\begin{abstract}
BACKGROUND

Microleakage in tooth/restoration interface is one of the major causes for any composite restoration failure. The composite resin usage without any adhesive system on cervical margins usually can cause microleakage because there is no or little enamel on it. This is facilitating shrinkage of the material and leaving a gingival gap.

The aim of this study was to evaluate the effect of microleakage in class V cavity using self-adhering flowable composite/selfadhesive with the addition of acid etch.
\end{abstract}

\begin{abstract}
MATERIALS AND METHODS
The study was conducted on extracted 27 lower premolars. The teeth were prepared in class $\mathrm{V}$ cavities and filled with selfadhering flowable composite, total-etch adhesive system and flowable composite resin. All the teeth were randomly assigned into 3 groups: Group 1: 9 cavities restored with self-adhering flowable composite without etching, Group 2: 9 cavities restored with selfadhering flowable composite with etching only and Group 3: 9 cavities restored with flowable composite with total etch system. After being polished, the teeth were thermocycled 200 times, then it was coated with nail polish and immersed in methylene blue for 24 hours. They were sectioned longitudinally and using the stereomicroscope with 20 times magnification dye penetration was measured. The results were analysed using Kruskal-Wallis Test and Mann-Whitney at 0.05 level of significance.
\end{abstract}

\section{RESULTS}

There was a statistically significant effect on the acid etch addition in gingival dye penetration of self-adhering flowable composite $(\mathrm{p}<0.05)$.

\section{CONCLUSION}

Self-adhering flowable composite alone was enough to establish good marginal sealing with enamel margins but was inadequate to establish good marginal sealing with dentin margins.

\section{KEYWORDS}

Microleakage, Class V Restoration, Self-Adhesive Composite Resin.

HOW TO CITE THIS ARTICLE: Dennis, Aswal D, Anastasia. The effect of microleakage in class V cavity using self-adhering flowable composite with the addition of acid etch. J. Evolution Med. Dent. Sci. 2017;6(16):1276-1280, DOI: 10.14260/Jemds/2017/277

\section{BACKGROUND}

Class V lesions are those occurring at the cervical aspect of the buccal or lingual surfaces of teeth. Conventionally, based on the aetiology, a class $\mathrm{V}$ lesion is broadly classified as Carious and Non-Carious lesions. The non-carious cervical lesions are further categorised into abrasion, erosion and abfraction. ${ }^{1}$

Abfraction can occur because of masticatory forces are at nonaxial teeth causing pressure on the cervical part of the tooth that is weak. The pressure can trigger cervical tooth loss directly or indirectly.

Financial or Other, Competing Interest: None.

Submission 18-01-2017, Peer Review 09-02-2017,

Acceptance 17-02-2017, Published 23-02-2017.

Corresponding Author:

Dr. Dennis,

Jalan Alumni No.2,

Kampus USU. Medan 20155,

Sumatera Utara,

Indonesia.

E-mail: dennis_dionisius@yahoo.co.uk

DOI: $10.14260 /$ jemds $/ 2017 / 277$
Erosion may represent a more appropriate term to describe the surface of the tooth that is lost due to chemical or electrochemical reaction. According to research, the food substance with a $\mathrm{pH}$ less than 5.5 can accelerate the process of demineralisation of teeth. Abrasion can occur due to incorrect method of brushing teeth, dental floss usage errors and toothpicks, or other bad habits. ${ }^{2-3}$

Problems with restoring class $\mathrm{V}$ cavity include difficulty in obtaining moisture control, adhesion with different substance (Enamel and Dentin) and anatomy of cementoenamel junction. ${ }^{2-5}$ The exudation of gingival fluid is possibly one of the challenges to adhesion in cervical region, which is either on supra or subgingival. Factors that influence the difficulty in manipulating marginal adaptation is polymerisation, shrinkage, viscosity, and material flexibility on cavity wall. ${ }^{6}$

One of the major aspect in succeeding composite restoration is - there should not be any microleakage.? Flowable restorative resins with a low viscosity are recommended as the material of choice for restoring Class $\mathrm{V}$ cavities. These new composite resin systems reportedly bond to dentin and enamel without the application of an adhesive bonding agent. They combine adhesive and composite technology because it contains glycerophosphate dimethacrylate (GPDM) monomer adhesive and acidic 
phosphate group as found also in other adhesive system. ${ }^{8} \mathrm{~A}$ research done in University of Siena shows that self-adhering flowable composites have less microleakage (15.9\%) than self-etch adhesive with flowable composites $(27.7 \%){ }^{9}$

One important aspect of long-term success of composite resin restorations is the presence or absence of microleaks. Microleaks can be defined as the gap/space that cannot be detected clinically by the presence of bacteria, fluids, molecules and ions between the cavity walls of restorative material. Fluids can penetrate into the dentin to the pulp, causing post-treatment sensitivity, recurrent caries, inflammation of the pulp, staining and restoration failures. So, to prevent the microleakage, flowable composite resin is recommended because it has low viscosity and good elasticity. ${ }^{10}$

Flowable composite with low viscosity is recommended as the right material in the restoration of class $\mathrm{V}$ composite cavity is very easy to use, because it has a low viscosity and is highly aesthetic. ${ }^{11}$ Injectability of low viscosity flowable composite is obtained from the low percentage of filler or of modification monomer resin. Flowable composite is indicated for pit and fissure sealant, marginal defect repair, as a liner in deep cavities. Low modulus and high flow capacity can reduce stress and reduce the microleakage and debonding. ${ }^{12}$

Meanwhile, many researchers show that tight and durable bonding to enamel and dentin can be achieved by acid etch role, such as $30-40 \%$ phosphoric acid. It will form microporosity on enamel and penetration of the monomer in creating mechanical retention. ${ }^{9}$ On the other hand, dentin adhesion cannot be predicted because of tubular dentin structure and high organic contents. Total-etch technique can demineralise enamel as well as dentin and can open dentinal tubules to improve bond strength by creating impregnated resin tags. However, using a total-etch technique, phosphoric acid could also cause collapsed collagen fibres as dentin was demineralised. ${ }^{10}$

The addition of acid etching will remove the smear layer, enamel and dentin demineralisation exposing the collagencollagen fibrils that can form a better attachment to the tooth structure. In class $\mathrm{V}$ cavity, where it is located near the area cementoenamel junction (CEJ) which consists of thin layer of enamel, adhesion between restorative material and tooth structure is more difficult to achieve. Self-adhering flowable composite itself has glycerophosphate dimethacrylate monomer (GPDM) that serves as etching and bonding to the tooth structure so that the addition of acid etching is no longer needed on the use of this flowable composite resin. However, it should be investigated further if the addition of acid etching on a self-adhering flowable composite will produce a better attachment or just give the same effect with self-adhering flowable composite restorations.

New methods to shorten the time of adhesion procedure are more popular recently. In 2009, the latest innovation in technology of composite resin and adhesive on one product, namely Self-Adhering Flowable Composite was introduced. ${ }^{12-}$ ${ }^{14}$ Self-adhering flowable composite material was introduced to be an alternative material in order to shorten restorative procedures because it does not require bonding application stage separately. Composite material is indicated for the restoration of cavities of small Class I and restoration base/liner Class I and II, pit and fissure sealant, for repairing defects of enamel, block undercuts, build-up restoration, restoration in areas which are not exposed to pressure, incisal abrasion and to improve porcelain-like class $\mathrm{V}$ cavities. A research conducted by the University of Siena showed that self-adhering flowable composite has a smaller microgap $(15.9 \%)$ when compared to the self-etch adhesive system with traditional flowable composites $(27.7 \%$ and $27.8 \%)$. Self-adhering flowable composite is able to bind to the surface of the teeth properly without the prior bonding applications because it has glycerophosphate dimethacrylate (GPDM) adhesive monomer and acidic phosphate group. ${ }^{15}$

The objective of this study was to evaluate the effect of microleakage of class $\mathrm{V}$ cavity using self-adhering flowable composite with the addition of acid etch.

\section{MATERIALS AND METHODS}

Twenty seven human lower premolars, extracted for orthodontic purposes, were selected for this study. After being stored in saline solution at room temperature, teeth surfaces were cleaned with pumice and water. Teeth with class $\mathrm{V}$ cavities were prepared on the buccal surface with cavity dimensions of $4 \mathrm{~mm}$ width, $2 \mathrm{~mm}$ height and $2 \mathrm{~mm}$ depth. A periodontal probe was used to measure cavity dimensions. Cavities were finished with high-speed handpiece on enamel with \#2 round diamond burs and round tungsten carbide (steel bur) on dentin. The cavities were cleaned and dried with absorbent paper. The 27 teeth were assigned into 3 groups: Group 1: 9 cavities were restored with self-adhesive (Vertise Flow) with provided dispensing tip. Used the provided brush to apply Vertise Flow to the entire cavity with moderate pressure for $20 \mathrm{sec}$. to obtain a thin layer $(<0.5 \mathrm{~mm})$. Light cured for $20 \mathrm{sec}$., then dispensed Vertise Flow again until it has fully restored the cavity, light cured for 20 sec. Group 2: 9 cavities were restored with selfadhesive with etching only with $37.5 \%$ phosphoric acid for 15 sec., then cleaned and dried until moist environment was achieved with absorbent paper. Vertise Flow was dispensed to cavity $<0.5 \mathrm{~mm}$ and using the provided brushes, applied to the entire cavity for 20 seconds. Light cured 20 seconds and reapplied Vertise Flow until it is fully restored. Light cured 20 seconds again. Group 3: Applied acid etch for 15 seconds with $37.5 \%$ phosphoric acid. Cleaned and dried with absorbent paper until moist environment was noted. Applied bonding agent to the cavities and given gentle air blow for 10 seconds, then light cured for 20 seconds. Revolution Formula was applied and light cured for 20 seconds.

The teeth were polished with fine diamond and extra fine diamond bur, then after that polished with OptiDisc bur and silicon bur. The teeth were maintained in saline for $24 \mathrm{~h}$. at $37^{\circ} \mathrm{C}$. After thermocycling, all the teeth surfaces were isolated with two layers of nail varnish (except the restoration and $1 \mathrm{~mm}$ around the margins). The apexes of the teeth received four layers of nail varnish, to avoid penetration of the tracer towards the pulp. After the completion of the restorative procedures, the specimens were stored in a buffered $2 \%$ aqueous solution of methylene blue for 24 hours. The specimens were rinsed in running tap water for 20 minutes and allowed to air dry. The specimens were then sectioned buccolingually through the centre of the restorations with disc bur. The dye penetration depth measurements were done through stereomicroscope with 20 times magnification as in Owens and Johnson scoring system. ${ }^{11}$ Mean dye penetration depth values were expressed 
in $\mathrm{mm}$, and data were analysed by Kruskal-Wallis Test and Mann-Whitney Test at the 0.05 level of significance.

\section{RESULTS}

Dye penetration score to show microleakage on 3 tested groups are presented in table 1 . The highest microleakage values were found with gingival margins when compared to occlusal and the highest gingival microleakage value was found at self-adhesive composite resin group without acid etch and flowable composite resin with total etch system.

\begin{tabular}{|c|c|c|c|c|c|c|}
\hline & \multicolumn{6}{|c|}{$\begin{array}{r}\text { Microleakage Score } \\
\end{array}$} \\
\hline Groups & Tested Groups & Source & $\mathbf{0}$ & 1 & 2 & 3 \\
\hline \multirow{2}{*}{1} & \multirow{2}{*}{$\begin{array}{l}\text { Self-adhesive } \\
\text { composite }\end{array}$} & Occlusal & 2 & 4 & 3 & - \\
\hline & & Gingival & - & 1 & 2 & 6 \\
\hline \multirow{2}{*}{2} & \multirow{2}{*}{$\begin{array}{c}\text { Self-adhesive } \\
\text { composite with } \\
\text { acid etch }\end{array}$} & Occlusal & 6 & 2 & - & 1 \\
\hline & & Gingival & - & 6 & 3 & - \\
\hline \multirow{2}{*}{3} & \multirow{2}{*}{$\begin{array}{c}\text { Flowable } \\
\text { composite with } \\
\text { total etch two- } \\
\text { step system }\end{array}$} & Occlusal & - & 6 & 3 & - \\
\hline & & Gingival & - & 3 & 1 & 5 \\
\hline & $\begin{array}{l}\text { Table 1. Micro } \\
\text { Penetration }\end{array}$ & akage & & & & \\
\hline
\end{tabular}

\begin{tabular}{|c|c|c|c|}
\hline \multirow{2}{*}{ Groups } & \multirow{2}{*}{ N } & \multicolumn{2}{|c|}{ Asymp. Sig. } \\
\cline { 2 - 4 } & 9 & Occlusal & Gingival \\
\hline 1 & 9 & \multirow{3}{*}{0.049} & 0.011 \\
2 & 9 & & \\
3 & $\mathbf{2 7}$ & & \\
\hline Total & & \\
\hline Table 2. Kruskal-Wallis Test Result showing effect of \\
Microleakage using Acid Etch Addition on \\
Self-adhering Flowable Composite $(p<0.05=*)$ \\
\hline
\end{tabular}

\begin{tabular}{|c|c|c|}
\hline \multirow{2}{*}{ Groups } & \multicolumn{2}{|c|}{ Asymp. Sig. } \\
\hline & Occlusal & Gingival \\
\hline 1 & \multicolumn{2}{|c|}{0.003} \\
\hline 2 & \multicolumn{2}{|c|}{0.016} \\
\hline 3 & \multicolumn{2}{|c|}{0.044} \\
\hline \multicolumn{3}{|c|}{$\begin{array}{c}\text { Table 3. Mann-Whitney Test Result showing Effect of } \\
\text { Microleakage using Acid Etch Addition on } \\
\text { Self-adhering Flowable Composite }(p<0.05=*)\end{array}$} \\
\hline
\end{tabular}

\begin{tabular}{|c|c|c|c|}
\hline \multirow{2}{*}{ Groups } & \multirow{2}{*}{$\mathbf{N}$} & \multicolumn{2}{|c|}{ Asymp.Sig } \\
\hline & & Occlusal & Gingival \\
\hline 1 & 9 & \multirow{3}{*}{0.098} & \multirow{3}{*}{0.003} \\
\hline 2 & 9 & & \\
\hline Total & 18 & & \\
\hline 1 & 9 & \multirow{3}{*}{0.552} & \multirow{3}{*}{0.478} \\
\hline 3 & 9 & & \\
\hline Total & 18 & & \\
\hline 2 & 9 & \multirow{3}{*}{0.016} & \multirow{3}{*}{0.044} \\
\hline 3 & 9 & & \\
\hline Total & 18 & & \\
\hline \multicolumn{4}{|c|}{$\begin{array}{c}\text { Table 4. Mann-Whitney Test Result showing Effect of } \\
\text { Microleakage using Acid Etch Addition on } \\
\text { Self-adhering Flowable Composite }(p<0.05=*)\end{array}$} \\
\hline
\end{tabular}

\section{DISCUSSION}

The smallest microleakage score between 3 tested groups is in self-adhering flowable composite group with acid etch addition, which can explain to us that bonding with acid etch addition is better than single use of self-adhering flowable. Acid etching removes the smear layer, demineralised inorganic enamel structure, forms microporosity to get good mechanical retention. ${ }^{10}$

Smear layer containing hydroxyapatite and denaturated collagen-collagen can weaken adhesion because monomer resin does not penetrate deep enough into the dentine surface. Smear layer can block dentinal tubules which is usually referred to as smear plugs. Smear plugs lie at a depth of $1-10 \mu \mathrm{m}$ and are located adjacent to the smear layer. Disposal of smear layer in whole or in part can be achieved by the addition of acid etching. More the aggressive acidity of an etching solution more the smear layer, so smear plugs will be removed. Strong acid etching solution does not only remove smear layer but also causes the demineralisation of dentin up to a depth of 1-5 $\mu \mathrm{m}$. When demineralised dentin is added to the phosphoric acid, etching will expose collagen-collagen fibrils. Dentinal tubules will be shaped like a funnel when peritubular demineralised dentin and dentinal tubules are widened by acid etching process. Collagen fibrils that have been exposed will function as a network of micro-retentive for micromechanical interlocking of the polymer resin. The primary function of the adhesive resin is to fill the gap among the collagen fibrils. At the time of polymerisation, hybrid layer and resin tags will form and shape mechanical retention

Our data in (Table 1) is not in agreement with Mine et al research that shows self-adhering flowable composite (Dyad Flow) has intimate adaptation to dentin and enamel surface, while our data is in agreement with the findings of Al-Shekhli et al who found that microleakage score penetration in selfadhesive with acid etch is smaller than single step selfadhesive. ${ }^{12,13}$

The higher leakage detected in gingival wall compared with occlusal wall can be related to the structure of these two walls (Table 1, 2 \& 3). Wet dentin surface helps bonding agent to penetrate into dentin tubules and collagen. However, good dentin and resin adhesion will cause a restoration to achieve adequate sealing. ${ }^{14}$ Marginal adaptation becomes even more difficult in class $\mathrm{V}$ cavities where there is little or no enamel at the cervical margins, and the restoration comes in contact with cementum. This decreases adhesion considerably facilitating the dislodgment of the material towards occlusal during polymerisation, because adhesion of a composite resin to enamel surface is better when compared to dentin surface which explains us the presence of microleakage on cementum (Cervical part) more than in enamel (occlusal part). ${ }^{13}$

Self-adhering flowable composite resin-based material technology has the attachment that uses glycerophosphate dimethacrylate (GPDM). Glycerophosphate dimethacrylate (GPDM) is an adhesive monomer having a functional group of acidic phosphate to enhance the adhesion to the tooth structure. GPDM is an adhesive monomer which serves as a phosphate acidic etching and bonding to the acidic phosphate groups. ${ }^{12}$ Self-adhering flowable has the chemical structure which is not far different from the total etch adhesive system. ${ }^{15}$ GPDM also has two methacrylate functional groups for copolymerisation with other methacrylate monomers to form a polymetric crosslinking network and to enhance the crosslinking density and to improve the mechanical strength for the polymerisation. ${ }^{12}$ These resins also have hydroxyethyl 
methacrylate (HEMA), functional group monomer usually used in adhesives to enhance the penetration of moisture and resin to dentin. According to SEM analysis conducted by Poss SD, self-adhering flowable composite resin has a tight interfacial adaptation to the tooth surface, indicating that this material has a durable adhesion to the restoration surface.

Self-adhering flowable composite is the latest generation of flowable composite resin in which also contains the all-inone adhesive. ${ }^{12-14}$ Self-adhering flowable composite is able to bind to the surface of the teeth properly without the prior bonding applications because it has a glycerol phosphate dimethacrylate (GPDM). Glycerol phosphate dimethacrylate (GPDM) is an adhesive monomer having a functional group of acidic phosphate to improve the attachment to the structure gigi. ${ }^{12}$ In modifying the smear layer cavities, self-adhering flowable composite has an acidity of $\mathrm{pH} 1.9$ and will be neutral (pH 6, 5-7) at the time of polymerisation. Smear layer that has been modified is used for attachment to the tooth structure through micromechanical retention as the result of polymerising the monomer interpenetration of self-adhering flowable, collagen fibres and hydroxyapatite crystals on the smear layer. First layer on the application of self-adhering flowable with sufficient pressure to increase the penetration of smear layer will create a similar attachment with $7^{\text {th }}$ generation dentin bonding agents.

Flowable composite resin generally shows shrinkage more than other conventional composite resin because its filler content is $60 \%$. The small amount of filler in flowable composite resin indicates that resin polymerisation shrinkage will be higher than self-adhesive with decreased resin deformation resistance (Table 4). ${ }^{15}$

In Table 2, the results of Kruskal-Wallis test showed scores of higher microleakage at gingival edge restoration in comparison to the edge of the occlusal restoration in all groups. This is because in cavity class $\mathrm{V}$ there is little or no enamel at the cervical margin. Adhesion of composite resin to enamel was proven to be better if compared to dentin. Moist dentin surfaces can provide both advantages and disadvantages for dentin bonding. Wetting liquid dentin surface may facilitate bonding agent to penetrate into the tubules and the collagen fibres. Factor in doing agitation method may also affect the results of microleakage greater at gingival edge.

Table 4 shows the results of a Mann-Whitney Test to find out the effect of the addition of acid etching on the resin composite self-adhering flowable composite, in group 1 and 2 there was no significant difference $(p>0.05)$ in the area of occlusal but there is significant $(p<0.05)$ difference in the gingival area. Marginal adaptation becomes more difficult in class $\mathrm{V}$ cavities where there is little or no enamel at the cervical margin. This reduces the adhesion of resin, and cavities during polymerisation because of adhesion of composite resins to enamel better than to dentin. It can be explained on the results that microleakage is more in the cementum (gingival edge) than in enamel (occlusal edge). ${ }^{8}$ The results of this study did not correspond with Burgess \& Cakir research that found no significant effect between the edge of the occlusal and gingival.

In table 4, Mann-Whitney Test showed no significant effect ( $p>0.05$ ) at occlusal and gingival in groups 1 and 3 . Although statistical test did not show significant effect but group 3 had greater microleakage among all samples showing presence of Methylene Blue dye penetration of $2 \%$ compared to the first group that there are only two samples with no dye penetration. The nature of the composite resin is highly dependent on the composition of the composite. Resin has better properties when it contains higher filler content, modulus and resistance on deformation. Conversely, the lower the filler content of the material, it has greater polymerisation shrinkage and in turn it will reduce its resistance on deformation. Flowable composite resins generally exhibit higher shrinkage stress when compared to other conventional composites because of high filler content owned flowable composite. Revolution Formula 2 shows the polymerisation shrinkage with high filler content of $60 \%$.

The results of research of Bektas et al in 2013, which stated that the self-adhering flowable composite has a resistance equal to the marginal adhesive system and flowable composite resin. However, it is not appropriate with research of Jaya $\mathrm{F}$ where the total-etch technique has a higher bond strength than the self-adhering flowable composite. Therefore, total-etch proved to have a stronger acidity ( $\mathrm{pH}$ 0.1-0.6) compared self-adhering composite ( $\mathrm{pH} 1.9$ )

In table 4, Mann-Whitney Test showed significant difference $(\mathrm{p}<0.05)$ in groups 2 and 3 at occlusal and gingival. Adhesion to enamel was accepted by many researchers as an attachment that is strong and durable, because the acid etching, such as $30-40 \%$ phosphoric acid, will form the microporosity on the enamel and causes the monomers penetrate forming mechanical retention. If composite resins are used for the restoration of the lesion, there will be a weak marginal adaptation. The main cause is the polymerisation shrinkage due to weak adhesion to dentin surface. Another reason for the lack of marginal adaptation of composite resin is thermal expansion coefficient differences between the restorative materials and tooth. In this research, contrary to research Ceballos 2003 which states that the use of total-etch adhesive system with two-step phases produces better adhesion on dentin.

\section{CONCLUSION}

The effect of microleakage is significantly lower with the addition of acid etch in self-adhering flowable composite. The results showed that in group of self-adhering flowable composite only $22 \%$ of the samples did not have microleakage.

There is no significant effect of acid etching addition of self-adhering flowable composite in occlusal margin, but significant effect only occurs in gingival margin. The addition of acid etch is unnecessary on enamel cavity while it is essential in dentin cavity to ensure good marginal sealing.

\section{REFERENCES}

[1] Suma B, Savitha S, Nandini S, Deivanayagam K. Management of class $\mathrm{V}$ lesions based on etiology. J Conserv Dent 2007;10(4):141-7.

[2] Cdos PR, Gonzales MR, Prado NA, et al. Restoration of noncarious cervical lesions: when, why, and how? Ind J Dent Article ID 687058 2012:2012:8.

[3] Perez CR. Alternative technique for class $\mathrm{V}$ resin composite restorations with minimum finishing /polishing procedures. Oper Dent 2010;35 (3):375-9. 
[4] Chandurkar AM, Metgud SS, Yakub SS, et al. Evaluation of microleakage in class $\mathrm{V}$ composite restoration using different technique of polymerisation. Int J Prosthodont and Res Dent 2012;2(1):10-15.

[5] Delvin H. Operative Dentistry. Berlin: Springer 2006; p. 101.

[6] Arambawatta K, Peiris R, Nanayakkara D. Morphology of cement-enamel junction in premolar teeth. J Oral Sci 2009;51(4):623-7.

[7] Singh SV, Gupta S, Jain P, et al. Microleakage evaluation of nano ceramics and nano composite resins using self etch adhesive in class $\mathrm{V}$ cavities using single increment technique. DJAS 2013;1(2):106-111.

[8] Swift EJ, Walter R. Vertise flow the evolution of adhesive technology. Inside Dentistry 2010:154.

[9] Mann NS, Makkar S, Sharma R. In vitro comparative evaluation of microleakage in newly introduced Dyad flow with total etch and self etch adhesives in class $\mathrm{V}$ resin composite restorations. JNDA 2015;15(1):33-8.
[10] Jaya F, Eriwati YK. Effect of surface treatment on adhesion to dentin. J PDGI 2012;60(1):35-42.

[11] Pashley DH, Tao L, Boyd L, et al. Scanning electron microscopy of the substructure of smear layers in human dentine. Arch Oral Biol 1988;33(4):265-70.

[12] Sadeghi M, Lynch CD, Shahamat N. Eigthteen-month clinical evaluation of microhybrid, packable and nanofilled resin composites in class I restorations. J Oral Rehabil 2010;37(7):532-7.

[13] Al-Shekhli AAR, Al-Aubi I, Ali NS, et al. Microleakage of fusio liquid dentin self-adhesive composite in class $\mathrm{V}$ cavities. Pak Oral Dental J 2015;35(2):278-81.

[14] Dharsono HDA. Restorasi resin komposit dengan teknik laminasi. tesis. bandung: program studi ilmu konservasi FKG Unpad. 2007:17-21.

[15] Baroudi K, Saleh AM, Silikas N, et al. Shrinkage behaviour of flowable resin-composites related to conversion and filler-fraction. J Dent 2007;35(8):6515. 